\title{
Revealing Stepwise Mechanisms in Dipolar Cycloaddition Reactions: Computational Study of the Reaction between Nitrones and Isocyanates
}

\author{
Andrea Darù, David Roca-López, Tomás Tejero, and Pedro Merino* \\ Laboratorio de Síntesis Asimétrica, Instituto de Síntesis Química y Catálisis Homogénea (ISQCH), Universidad de Zaragoza-CSIC, \\ 50009 Zaragoza, Aragón, Spain
}

\section{Supporting Information}

ABSTRACT: The mechanism of cycloaddition reactions of nitrones with isocyanates has been studied using density functional theory (DFT) methods at the M06-2X/cc-pVTZ level of theory. The exploration of the potential energy surfaces associated with two reactive channels leading to $1,2,4-$ oxadiazolidin-5-ones and 1,4,2-dioxazolidines revealed that the cycloaddition reaction takes place through a concerted mechanism in gas phase and in apolar solvents but a stepwise mechanism in polar solvents. In stepwise mechanisms, the first step of the reaction is a rare case in which the nitrone oxygen acts as a nucleophile by attacking the central carbon atom of the isocyanate (interacting with the $\pi$-system of the $\mathrm{C}=\mathrm{O}$ bond) to give an intermediate. The corresponding transition structure is stabilized by an attractive electrostatic interaction favored in a polar medium. The second step of the reaction is the ratelimiting one in which the formation of 1,2,4-oxadiazolidin-5-ones or 1,4,2-dioxazolidines is decided. Calculations indicate that formation of 1,2,4-oxadiazolidin-5-ones is favored both kinetically and thermodynamically independently of the solvent, in agreement with experimental observations. Noncovalent interactions (NCI) and topological analysis of the gradient field of electron localization function (ELF) bonding confirmed the observed interactions.

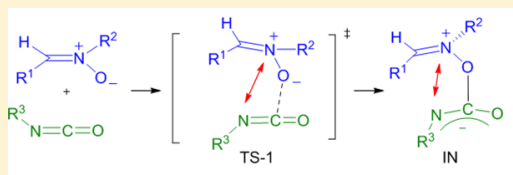

$\longleftrightarrow$ stabilizing electrostatic interactio
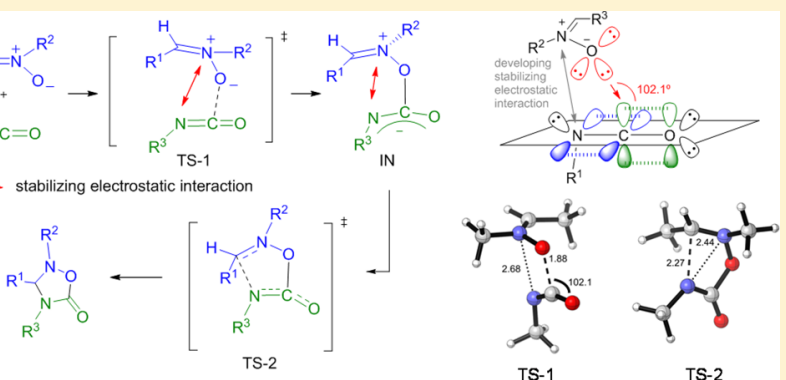

TS-2

\section{INTRODUCTION}

1,3-Dipolar cycloadditions between nitrones and alkenes are well-known reactions ${ }^{1}$ of considerable interest since the resulting isoxazolidines ${ }^{2}$ are versatile synthetic intermediates in the preparation of a variety of natural and related compounds. ${ }^{3}$ In addition to alkenes, nitrones also react with allenes ${ }^{4}$ and heteroallenes such as ketenes, ${ }^{5,6}$ isothiocyanates, ${ }^{7}$ and isocyanates. ${ }^{8}$ Depending on the type of compound one or both double bonds of the allene can participate in the cycloaddition reaction. In the reaction of nitrones with isocyanates, both the $\mathrm{C}=\mathrm{N}$ and $\mathrm{C}=\mathrm{O}$ bonds of the isocyanate can act as dipolarophiles ${ }^{9}$ to give 1,2,4-oxadiazolidin-5-ones ${ }^{10} 3$ and 1,4,2-dioxazolidines ${ }^{11} 4$, respectively (Scheme 1).

In the past decade, the origin of regio- and stereoselectivity of 1,3-dipolar cycloadditions of nitrones has been extensively studied through computational methods. There is a huge

Scheme 1. Cycloaddition Reaction between Nitrones and Isocyanates

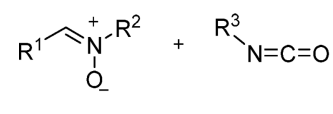

1

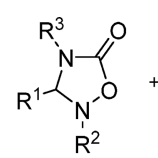

3

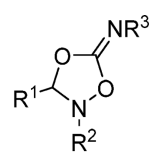

4 number of computational studies regarding typical 1,3-dipolar cycloaddition reactions between nitrones and alkenes. ${ }^{12}$ In some cases, these studies have demonstrated that the reactions are not concerted but stepwise. ${ }^{13}$ Other situations include pseudopericyclic reactions, ${ }^{14}$ and one-step two-stage processes $^{15}$ as in the case of the reaction with lithium ynolates. ${ }^{12 c}$ Despite all these studies, computational approaches to the reaction of nitrones with allenes and heteroallenes are scarce. In 2002, Kavitha and Venuvanalingam reported a DFT study of 1,3-dipolar cycloadditions involving allenes. ${ }^{16}$ Houk and Smith studied computationally the reaction pathway of a pericyclic cascade initiated by the cycloaddition between nitrones and ketenes. ${ }^{17}$ However, to the best of our knowledge, there are no computational studies concerning the cycloaddition reaction between nitrones and isocyanates. Following our interest in applying DFT methods to study nitrone reactivity, ${ }^{12 c, 18}$ we performed a full computational study of the reaction between nitrones $\mathbf{1}$ and isocyanates $\mathbf{2}$. Nitrone $\mathbf{1 a}$ and isocyanate $\mathbf{2 a}$ have been chosen as initial models for the study (Figure 1). In addition, introduction of a phenyl ring in the isocyanate (2b) and the nitrone at the $C-(\mathbf{1 b})$ and $N-(\mathbf{1 c})$ positions has been considered to study possible effects of the aromatic residue. Thus, a total of six reactions have been studied. The full study

Received: November 19, 2015

Published: December 18, 2015 


$\begin{aligned} \mathrm{R}^{1} \overbrace{1}^{3} \mathrm{~N}_{-}^{-} \mathrm{R}^{2} & \mathrm{R}_{\underset{\mathrm{N}}{\mathrm{N}}=\mathrm{C}=\mathrm{O}}^{3} \\ \text { 1a } \mathrm{R}^{1}=\mathrm{Me} \mathrm{R}^{2}=\mathrm{Me} & \text { 2a } \mathrm{R}^{3}=\mathrm{Me} \\ \text { 1b } \mathrm{R}^{1}=\mathrm{Ph} \mathrm{R}^{2}=\mathrm{Me} & \text { 2b } \mathrm{R}^{3}=\mathrm{Ph} \\ \text { 1c } \mathrm{R}^{1}=\mathrm{Me} \mathrm{R}^{2}=\mathrm{Ph} & \end{aligned}$

Figure 1. Nitrones and isocyanates.

has been carried out in dichloromethane, a solvent commonly used for carrying out the reaction, but for the purpose of comparison, additional studies in hexane, toluene, chloroform, and acetonitrile have also been performed.

\section{COMPUTATIONAL METHODS}

All of the calculations were performed using the Gaussian09 program. ${ }^{19}$ Molecular geometries were optimized with the M06-2X functional ${ }^{20}$ in conjunction with cc-pVTZ basis set. ${ }^{21}$ Truhlar and coworkers reported that, for examining barrier heights, a minimally augmented basis set such as the Dunning cc-pVTZ is appropriate. ${ }^{22}$ It was not necessary to augment the pVTZ basis with extra diffuse functions, as tests carried out by using the aug-cc-pVTZ basis resulted in changes in the relative energies of less than $1 \mathrm{kcal} / \mathrm{mol}$ while making calculations considerably more time-consuming. Moreover, the use of M06-2X in conjunction with the cc-pVTZ basis has provided excellent results in related calculations with nitrones. ${ }^{12 c, 18 b, c}$ We can therefore expect that the computed values should be sufficiently reliable in enabling us to draw meaningful conclusions. Analytical second derivatives of the energy were calculated to classify the nature of every stationary point, to determine the harmonic vibrational frequencies, and to provide zero-point vibrational energy corrections. The thermal and entropic contributions to the free energies were also obtained from the vibrational frequency calculations, using the unscaled frequencies. All transition structures were characterized by one imaginary frequency and were confirmed to connect to reactants and products by intrinsic reaction coordinate (IRC) calculations. ${ }^{23}$ The IRC paths were traced using the second-order González-Schlegel integration method. ${ }^{24}$ Solvent effects were calculated using the continuum solvation model (PCM). ${ }^{25} \mathrm{NCI}$ (noncovalent interactions) were computed using the methodology previously described. ${ }^{26}$ The NCI analysis has demonstrated their utility in the analysis of several reactions ${ }^{27}$ including cycloadditions. ${ }^{28}$ Data were obtained with the NCIPLOT program. ${ }^{29}$ The pictures were created with a density cutoff of $\rho=0.06 \mathrm{au}$, an isosurface value of $s=0.6$, and colored in the
$[-0.02,0.02]$ au range of " $\rho \cdot \lambda_{2} /\left|\lambda_{2}\right|$ " using VMD software. ${ }^{30}$ The electronic structures of stationary points were analyzed by the topological analysis of the gradient field of electron localization function (ELF) ${ }^{31}$ developed by Silvi and Savin. ${ }^{32}$ The ELF study was performed with the TopMod09 suite of programs $^{33}$ using the corresponding monodeterminantal wave functions of the structure of every point of the IRC. The topological analysis of the gradient field of ELF has been shown to be a powerful tool for the study of bonding changes along an organic reaction. ${ }^{34}$ Structural representations were generated using CYLView. ${ }^{35}$ Animation given in the Supporting Information was created by extracting and processing all points of the IRC with an in-house program and saving the corresponding images to create an animated GIF.

\section{RESULTS AND DISCUSSION}

Mechanistic Study. In principle, both concerted and stepwise mechanisms should be possible in a similar way to that reported for the reaction between nitrones and allenes. ${ }^{16}$ We considered two channels corresponding to the participation of $\mathrm{C}=\mathrm{N}$ (channel 1) and $\mathrm{C}=\mathrm{O}$ (channel 2) double bonds of the isocyanate in the cycloaddition reaction. Since nitrones 1ac are aldonitrones only $Z$-isomer was considered. ${ }^{36}$ Two different orientations of the substituent of the isocyanate (endo/ exo) for each channel was also taken into account, thus having a total of eight initial approaches leading to adducts 3 and $\mathbf{4}$ (Scheme 2). The different approaches for each regioisomer actually led to different isomers connected by a pyramidal inversion at the isocyanate nitrogen. Even though such a difference should be taken into consideration when considering the different transition structures, they lead to the same final product.

A preliminary analysis of the potential energy surface (PES) revealed the impossibility of approaching the reagents through the channel 1/endo path. The required approach to form the $\mathrm{C}-\mathrm{C}$ bond implies a direct collision between $\mathrm{R}^{1}$ and $\mathrm{R}^{3}$ thus preventing the formation of such a bond. Consequently, no transition structures TS2 could be located neither in the gas phase nor in the presence of dichloromethane as a solvent. The same was observed for all the reactions studied between nitrones $\mathbf{1 a}-\mathbf{c}$ and isocyanates $\mathbf{2 a , b}$. In consequence, we

Scheme 2. Plausible Mechanisms for the Reaction between Nitrones 1 and Isocyanates 2 (S and C series refers to stepwise and concerted pathways, respectively)

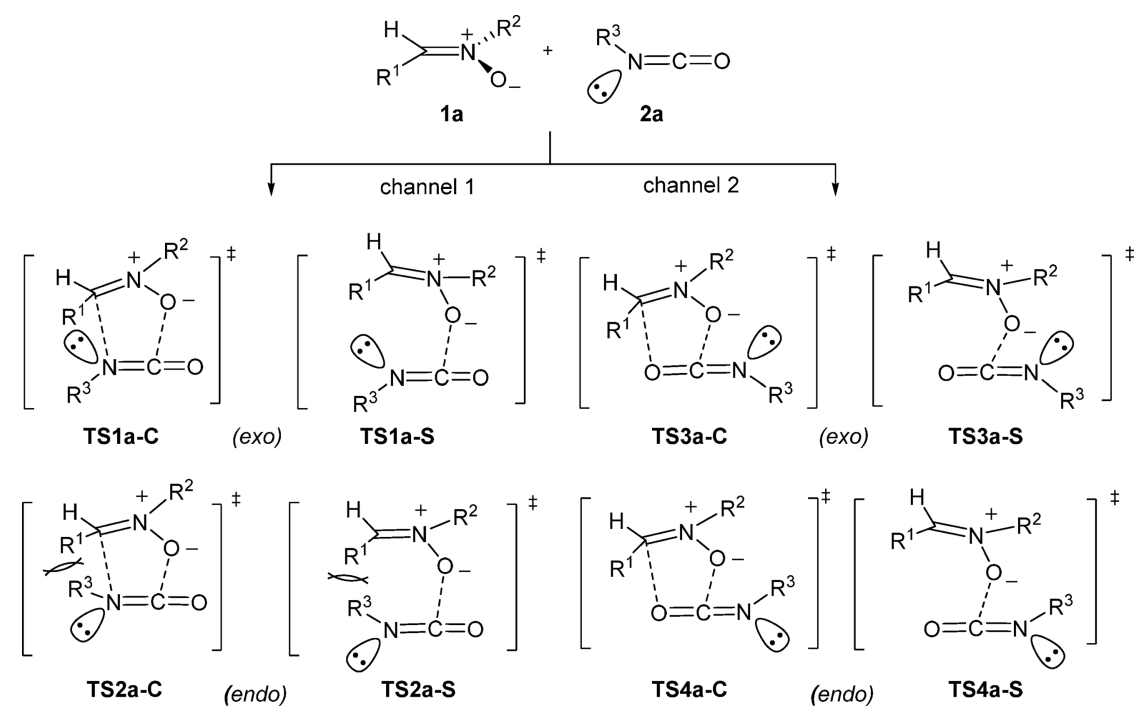


studied the three other paths corresponding to channel $1 /$ exo and channel 2, both exo and endo approaches.

Analysis of the various modes of reaction between 1a and 2a in the gas phase revealed highly asynchronous concerted transition structures for the three paths. The preferred one, TS1a-C, was that corresponding to channel 1/exo (energy barrier of $28.2 \mathrm{kcal} / \mathrm{mol}$ ), with differences of 2.5 and $3.3 \mathrm{kcal} /$ mol with respect to channel 2/exo (TS3a-C) and channel 2/ endo (TS4a-C), respectively. The obtention of compound 3a was shown to be exergonic by $15.4 \mathrm{kcal} / \mathrm{mol}$ but that of compound $4 \mathrm{a}$ was endergonic by $5.0 \mathrm{kcal} / \mathrm{mol}$. For the purpose of comparison we also carried out the study of the reaction between $\mathbf{1 b}$ and $\mathbf{2 b}$ in the gas phase, and identical results were obtained. Other approaches considering the possibility of a stepwise mechanism were not productive, and the corresponding transition structures could not be located. In all cases, calculations converged to one of the above-mentioned three concerted transition structures.

On the other hand, when solvent effects $\left(\mathrm{CH}_{2} \mathrm{Cl}_{2}\right)$ were considered, different results were obtained. An exploration of the PES for channel 1 revealed that the reaction takes place through a stepwise mechanism. No concerted transition structures could be located, and TS1a-S was located and characterized as the only possible transition structure. ${ }^{37} \mathrm{~A}$ similar situation was found for the channel 2/exo approach, and only TS3a-S could be located.

In contrast, in the case of the channel 2/endo approach the reaction was shown to be concerted and TS4a-C was located. Scheme 3 illustrates the preferred mechanisms for the reaction in dichloromethane.

The complete energy profiles corresponding to the processes illustrated in Scheme 3 are given in Figure 2. The stepwise processes are preferred, the concerted one being the less stable with a barrier of $31.2 \mathrm{kcal} / \mathrm{mol}$. From the two stepwise processes, that leading to compound $3 \mathbf{a}$ is the lowest in energy in good agreement with experimental observations. The ratelimiting step in the stepwise reactions corresponds to the second transition structure related to the formation of $\mathrm{C} 3-\mathrm{N} 4$ and $\mathrm{C} 3-\mathrm{O} 6$ bonds in $\mathbf{3 a}$ and $\mathbf{4 a}$, respectively. Thus, a relative difference of $4.3 \mathrm{kcal} / \mathrm{mol}$ was found in favor of TS5a with respect to TS6a. Again, the obtention of compound $\mathbf{4 a}$ is endergonic by $8.8 \mathrm{kcal} / \mathrm{mol}$ whereas the obtention of compound $3 \mathrm{a}$ is exergonic by $13 \mathrm{kcal} / \mathrm{mol}$.

Compounds 3 are favored both kinetically and thermodynamically. The reversibility of the formation of compounds 4 justifies the experimental observation that only isomers 3 are obtained in the cycloaddition between nitrones and isocyanates. ${ }^{10}$ The formation of compounds 4 has only been reported $^{11}$ as intermediates, not being isolated in any case.

For the stepwise mechanisms (channels 1 and 2/exo), TS1a$\mathbf{S}$ and TS3a-S were located as the only transition structures (Figure 3). The IRCs corroborated that TS1a-S and TS3a-S connect the reagents with open intermediates IN1a and IN2a, respectively. Due to the $s p$-character of the central carbon atom of the isocyanate, there are two possible side-orientations (leading to TS1a-S and TS3a-S) for the initial allylic nucleophilic attack of the nitrone oxygen, which takes place perpendicularly to the heteroallenic $\pi$-system (see below). The initial attack of the nitrone oxygen $\mathrm{O} 1$ to the isocyanate carbon C5 takes place in a completely eclipsed orientation between nitrone and isocyanate. Actually, only two possible orientations could be located, corresponding to TS1a-S (forming a bond distance of $1.88 \AA$ ) and TS3a-S (forming a bond distance of
Scheme 3. Reaction Mechanisms in Dichloromethane As a Solvent
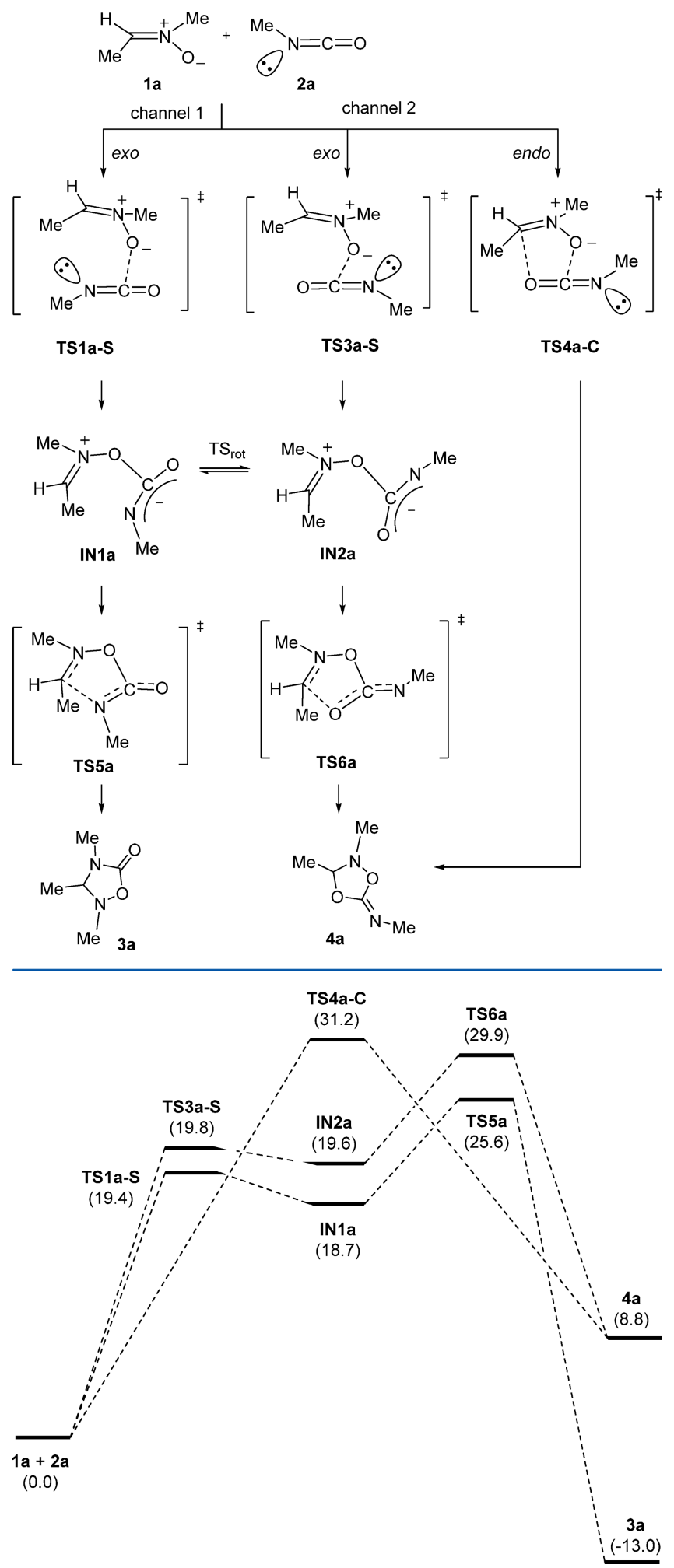

Figure 2. Energy profile (M06-2X/cc-pVTZ/PCM $=\mathrm{CH}_{2} \mathrm{Cl}_{2}$ ) for the reaction between 1a and 2a. Relative free energies are given in kcal/ mol.

$1.91 \AA$ ). The dihedral angles illustrated in Figure 3 are $2.4^{\circ}$ and $-0.6^{\circ}$ for TS1a-S and TS3a-S, respectively. 

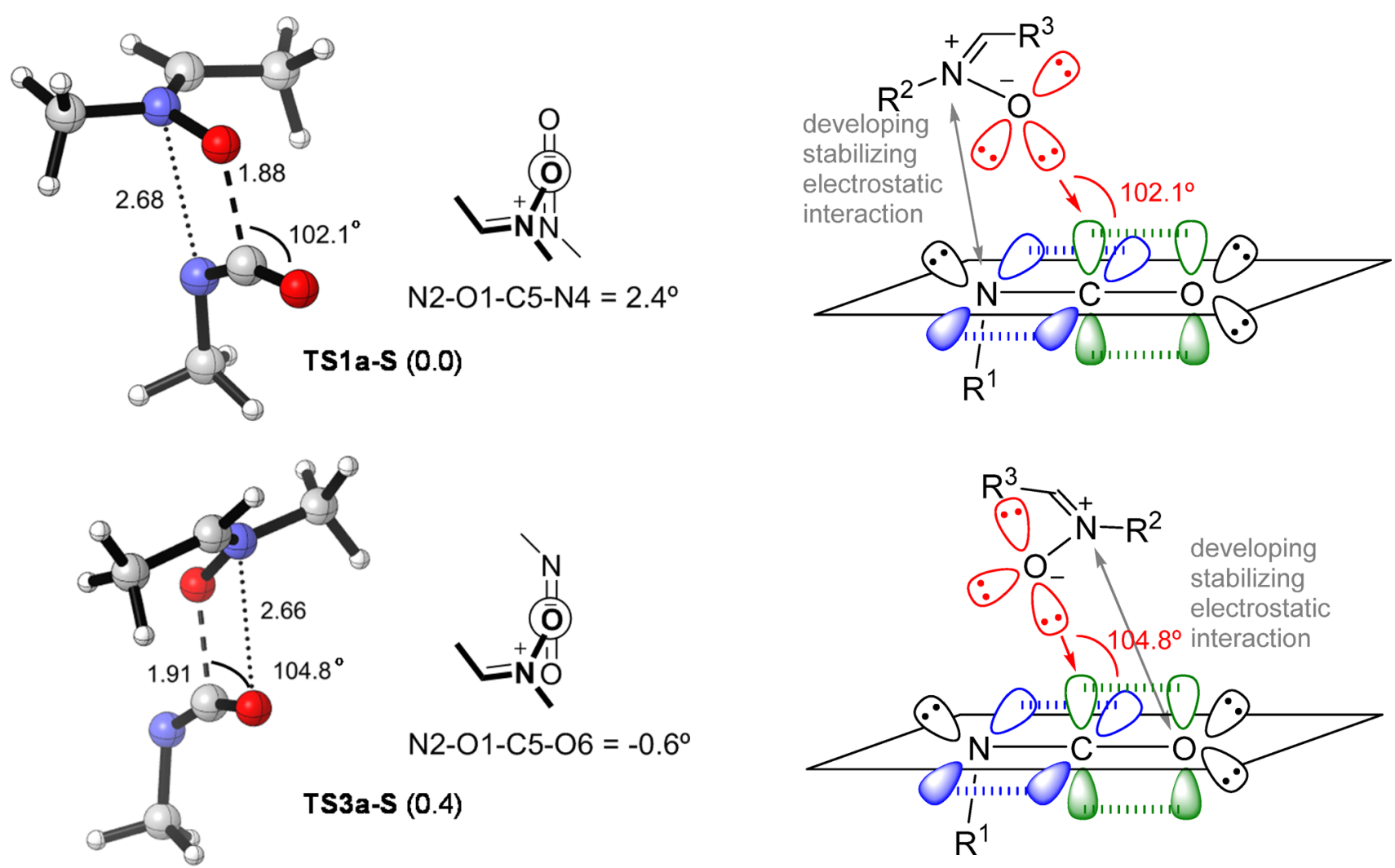

Figure 3. Optimized structures (M06-2X/cc-pVTZ/PCM $=\mathrm{CH}_{2} \mathrm{Cl}_{2}$ ) and relevant geometric parameters for TS1a-S and TS3a-S (distances are given in angströms).

Electron-deficient N2 and the electron-rich N4 (in TS1a-S) or O6 (in TS3a-S) are alligned in the transition structures, enabling a stabilizing electrostatic interaction between electrondeficient N2 and either electron-rich N4 or O6 atoms (distance N2-N4: $2.68 \AA ̊$ in TS1a-S; distance N2-O6: $2.66 \AA$ in TS3aS). That sort of electrostatic interactions had been predicted by von Schleyer and co-workers for anionic stepwise $(3+2)$ cycloadditions ${ }^{38}$ and observed by us in the addition of enolates to nitrones ${ }^{18 c}$ and the cycloaddition of nitrone ylides with alkenes. $^{39}$

This first step of the reaction is, actually, a nucleophilic addition to the central carbon of the isocyanate. The same eclipsed orientation has also been found in other processes involving nucleophilic attacks to isocyanates. Some representative examples are the dehydration of nitroalkanes by isocyanates in which one of the oxygen atoms of the nitro group attacks the central carbon of the isocyanate, ${ }^{40}$ the reaction between unsaturated azabicycles and isocyanates, ${ }^{41}$ the addition of isocyanates to fluoroalkylated $\alpha, \beta$-unsaturated imines, ${ }^{42}$ and the alcoholysis of isocyanates. ${ }^{43}$ By considering the orbital arrangement in isocyanates (in which the electron delocalization cannot be explained on the basis of electronegativity of atoms but on the basis of orbital interactions), ${ }^{44}$ the reason for the eclipsed orientation is that nucleophilic attack takes place through interaction of the nucleophile (nitrone oxygen) with the $\pi$-system of the $\mathrm{C}=\mathrm{O}$ bond (Figure 4 ).

Indeed, inspection of TS1a-S reveals a value of $102.1^{\circ}$ for the O1-C5-O6 angle in good agreement with a typical BürgiDunitz trajectory ${ }^{45}$ for the nucleophilic attack. Also, in the case of TS3a-S, the attack takes place on the $\pi$-system of the $\mathrm{C}=\mathrm{O}$ bond, in this case with an O1-C5-O6 angle of $104.8^{\circ}$. Both

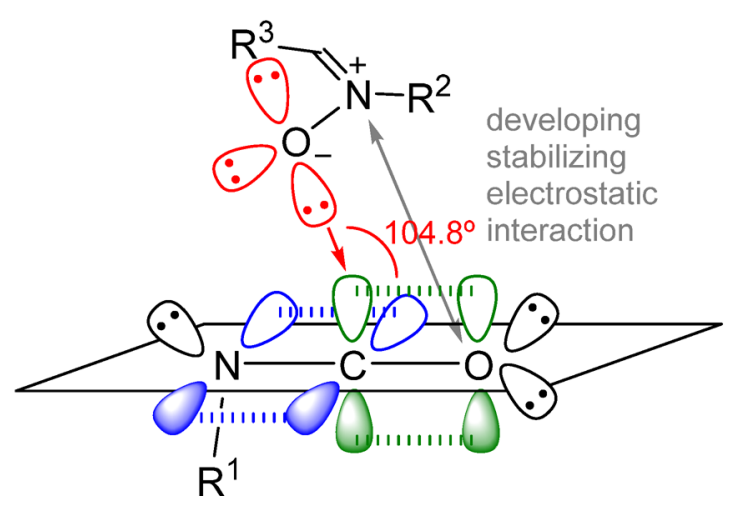

Figure 4. Orbital disposition in the first step of the reaction.

attacks are plausible, since the energy difference between TS1aS and TS3a-S is only $0.4 \mathrm{kcal} / \mathrm{mol}$, clearly within the error range in DFT calculations. In any case, this only affects the eclipsed orientation of the attack because the rate-limiting step of the reaction is the second one.

After transition structures TS1a-S and TS3a-S, intermediates IN1a and IN2a (Figure 5) are formed. The eclipsed conformation is maintained in intermediates IN1a and IN2a with dihedral angle values of $0.7^{\circ}$ and $0.1^{\circ}$, respectively. In fact, as illustrated in Figure 2, those intermediates are quite close in energy to the corresponding previous transition structures (energy differences of 0.7 and $0.2 \mathrm{kcal} / \mathrm{mol}$ between TS1a-S and IN1a, and TS3a-S and IN2a, respectively).

The developing stabilizing electrostatic interactions mentioned above are also present in intermediates IN1a (distance N2-N4: $2.56 \AA$ ) and IN2a (distance N2-O6: $2.55 \AA$ ) and arise from the delocalized negative charge on the N4-C5-O6 system. In fact, electron-deficient N2 and electron-rich N4 (in IN1a) or O6 (in IN2a) remain alligned. These interactions stabilize both the transition structures and the intermediates. The natural NBO charges of the atoms, given in Table 1, are also in agreement with a partial positive charge at N2 and a delocalized negative charge between $\mathrm{N} 4$ and O6.

The intermediates IN1a and IN2a can interconvert by rotation around the $\mathrm{O} 1-\mathrm{C} 5$ bond, but such interconversion is negligible since barriers of ca. $25 \mathrm{kcal} / \mathrm{mol}$ above the intermediates ( $44 \mathrm{kcal} / \mathrm{mol}$ above ground state) were found for the two possible rotational transition structures (see Supporting Information). The high barriers found for the rotational interconversion of IN1a and IN2a can be justified by the presence of the stabilizing electrostatic interaction. So, it is expected that both intermediates are formed from the corresponding transition structures through different channels. 

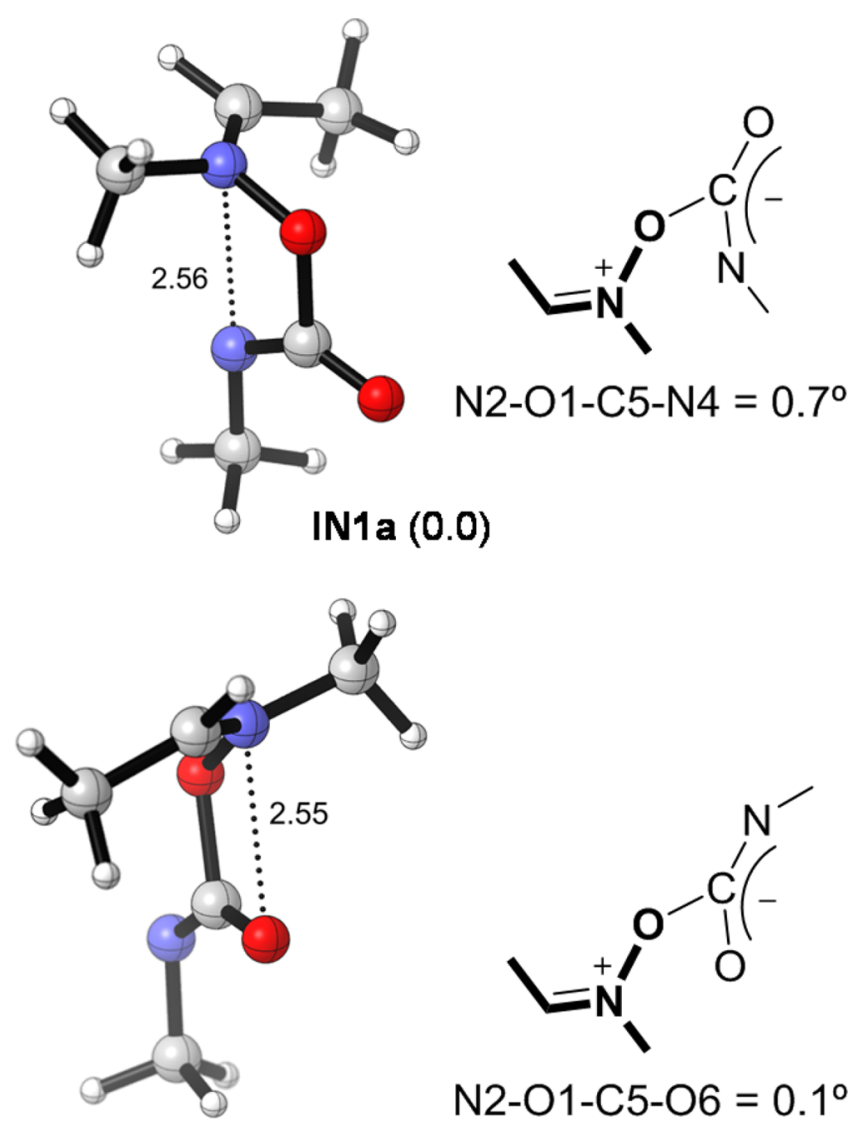

IN2a (0.9)

Figure 5. Optimized structures (M06-2X/cc-pVTZ/PCM $=\mathrm{CH}_{2} \mathrm{Cl}_{2}$ ) and relevant geometric parameters for IN1a and IN2a (distances are given in angströms).

Table 1. Natural NBO Charges of TS1a-S, TS3a-S, IN1a, and IN $2 a^{a}$

\begin{tabular}{lrrrr|} 
& TS1a-S & TS3a-S & \multicolumn{1}{c}{ IN1a } & \multicolumn{1}{c}{ IN2a } \\
\hline O1 & -0.451 & -0.577 & -0.451 & -0.448 \\
N2 & 0.063 & 0.084 & 0.062 & 0.060 \\
C3 & 0.270 & 0.177 & 0.270 & 0.265 \\
N4 & -0.742 & -0.642 & -0.742 & -0.685 \\
C5 & 0.850 & 0.891 & 0.850 & 0.832 \\
O6 & -0.741 & -0.658 & -0.741 & -0.769
\end{tabular}

${ }^{a}$ Charges of interacting atoms are given in italic.

After formation of intermediates IN1a and IN2a, products 3a and $4 \mathbf{a}$ are formed through TS5a and TS6a, respectively. The second transition structures TS5a and TS6a (Figure 6) look qualitatively similar to forming bond distances of $2.27 \AA$ (C3N4) and $2.08 \AA$ (C3-O6), respectively.

The observed difference in the forming bonds is in agreement with different $\mathrm{C}-\mathrm{N}$ and $\mathrm{C}-\mathrm{O}$ bond formation. A close inspection of TS5a revealed the transient situation between the favorable electrostatic interaction present in IN1a and the new forming C3-N4 bond. In fact, in TS5a N4 is placed at interacting distances of both C3 (2.27 A) and N2 $(2.44 \AA)$ indicating the displacement of the charge from an electrostatic interaction to the formation of a new bond. The same situation is observed for TS6a in which O6 is placed at

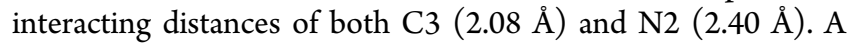
noncovalent analysis (NCI) confirmed the electrostatic

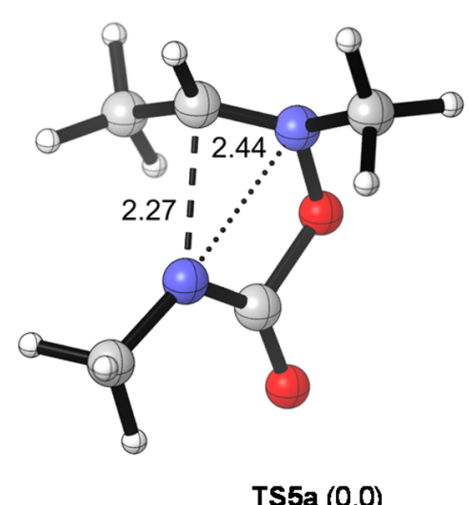

TS5a (0.0)

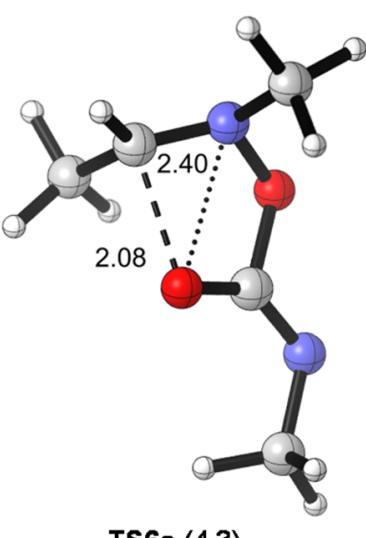

TS6a (4.3)
Figure 6. Optimized structures (M06-2X/cc-pVTZ/PCM $=\mathrm{CH}_{2} \mathrm{Cl}_{2}$ ) and relevant geometric parameters for TS5a and TS6a (distances are given in angströms).

interactions in transition structures (TS1a-S and TS3a-S) and intermediates (IN1a and IN2a) and showed the formation of new bonds (through TS5a and TS6a) at the expense of breaking such interactions (see Supporting Information).

In the case of channel 2/endo TS4a-C was located as the only transition structure (Figure 7). The IRC for TS4a-C

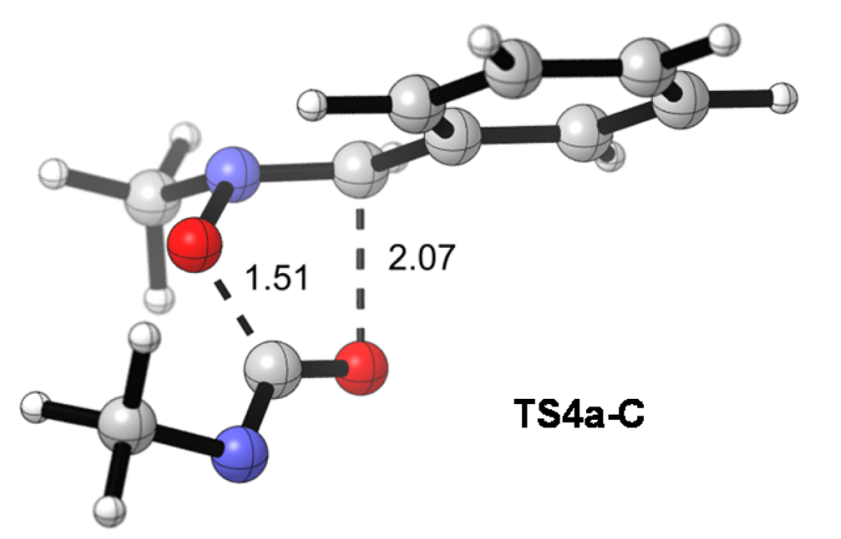

Figure 7. Optimized structures (M06-2X/cc-pVTZ/PCM $=\mathrm{CH}_{2} \mathrm{Cl}_{2}$ ) and relevant geometric parameters for TS4a-C (distances are given in angströms).

demonstrated the connection between the reagents and product 4a. This transition structure is similar to that found in the gas phase showing high asynchronicity although IRC confirmed the concertedness of the process. The asynchronicity of the ransition structure reveals a very early formation of the O1-C5 bond (forming bond distance: $1.51 \AA$ ) with respect to the C3-O6 bond (forming bond distance: $2.07 \AA$ ). For a detailed discussion on the evolution of population density (through an ELF analysis) along the reaction path, see Supporting Information.

Very similar results were obtained when aromatic rings were introduced in the models (reaction of $\mathbf{1 a}$ with $\mathbf{2} \mathbf{b}$ and reactions of $\mathbf{1 b}, \mathbf{c}$ with $\mathbf{2 a , b}$ ). In all cases, the formation of 1,2,4oxadiazolidin-5-ones 3 takes place through a stepwise exo mechanism, the corresponding concerted process not being found. Also, for the formation of 1,4,2-dioxazolidines 4 competitive stepwise and concerted mechanisms are found for exo and endo channels, the latter always being the less stable. In all studied reactions (see Supporting Information) the 
formation of isomers 3 was found to be favored both kinetically and thermodynamically.

Experimentally, the reaction is usually carried out in less polar solvents such as toluene, ${ }^{8 a, 10}$ dichloromethane, ${ }^{8 c, 9,11}$ and chloroform; ${ }^{10 c, d}$ there only is one report in which the reaction is reported to be performed in acetonitrile. ${ }^{8 \mathrm{~d}}$ In order to better appreciate the solvent effect we also evaluate the reaction between $1 \mathrm{a}$ and $\mathbf{2 a}$ in additional solvents, i.e., hexane, toluene, chloroform, and acetonitrile. These solvents are a good representation of different dielectric constants and polarity (Table 2).

Table 2. Solvent Properties and Predictions of Calculations (M06-2X/cc-pVTZ) for the Reaction between $1 \mathrm{a}$ and $2 \mathrm{a}^{a}$

$\begin{array}{lcclc} & \varepsilon & \text { polarity }^{a} & \text { mechanism } & \text { product } \\ \text { hexane } & 1.88 & 0.009 & \text { concerted } & \text { 3a } \\ \text { toluene } & 2.38 & 0.099 & \text { concerted } & \text { 3a } \\ \mathrm{CHCl}_{3} & 4.81 & 0.259 & \text { stepwise } & \text { 3a } \\ \mathrm{CH}_{2} \mathrm{Cl}_{2} & 8.93 & 0.309 & \text { stepwise } & \text { 3a } \\ \mathrm{CH}_{3} \mathrm{CN} & 37.5 & 0.460 & \text { stepwise } & \text { 3a }\end{array}$

${ }^{a_{T}}$ The values for relative polarity are normalized from measurements of solvent shifts of absorption spectra and were extracted from Reichardt, C. Solvents and Solvent Effects in Organic Chemistry, 3rd ed.; WileyVCH Publishers: 2003.

In apolar solvents such as hexane and toluene, all pathways occur through concerted mechanisms, the transition structures being almost identical to those obtained in the gas phase. On the other hand, calculations in chloroform and acetonitrile provided identical results to those obtained with dichloromethane. In all cases the obtention of 1,2,4-oxadiazolidin-5ones 3a are preferred, independently of the solvent (in hexane and toluene through a concerted mechanism and in dicholoromethane, chloroform, and acetonitrile through a stepwise mechanism). Also, competitive concerted and stepwise mechanisms were found for the formation of 1,4,2-dioxazolidines $\mathbf{4 a}$, and as in dichloromethane, the stepwise pathway was lower in energy than the concerted one. These results demonstrate that a moderate polarity like that of chloroform is sufficient in stabilizing polar TSs and intermediates, revealing their existence and leading to stepwise mechanisms. These results could be of utility in those cases in which a switch of mechanism involves the formation of different products. In the case of the reaction between nitrones and isocyanates both kinetics and thermodynamics point toward the formation of 1,2,4-oxadiazolidin-5-ones 3a.

\section{CONCLUSIONS}

In summary, in the reaction of nitrones with isocyanates concerted and stepwise mechanisms can be considered depending on the reaction media. The study of the reaction in the gas phase or in apolar solvents (hexane and toluene) exclusively led to concerted mechanisms irrelative of the pathway of the reaction considered. With moderately polar (dichloromethane and chloroform) and polar (acetonitirle) solvents, stepwise mechanisms for both channels involving $\mathrm{C}=$ $\mathrm{N}$ and $\mathrm{C}=\mathrm{O}$ bonds of the isocyanate were realized. Calculations predict that formation of 1,2,4-oxadiazolidin-5ones 3 is favored over 1,4,2-dioxazolidines 4 , independently of the media, both kineticallly and thermodynamically, in agreement with experimental observations. For reactions in polar solvents, the formation of 1,2,4-oxadiazolidin-5-ones 3 only takes place through a stepwise mechanism (other approaches being sterically hindered). On the other hand, formation of 1,4,2-dioxazolidines 4 can take place through stepwise and concerted mechanisms, the former being energetically preferred.

The concerted mechanisms (those in gas phase, in hexane, toluene, and the less favored pathway in polar solvents) are very similar and rather asynchronous. In all cases the formation of the $\mathrm{C}_{\text {isocyanate }}-\mathrm{O}_{\text {nitrone }}$ bond takes place at a very early stage of the reaction (as confirmed by topological ELF analysis). In the stepwise mechanisms the first step of the reaction consists of the nucleophilic attack of the nitrone oxygen to the central $s p$ carbon of the isocyanate. It takes place through a totally eclipsed approach of the nitrone and the isocyanate as a consequence of an attractive electrostatic interaction between the nitrone nitrogen and either the nitrogen atom or the oxygen atom of the isocyanate. Admittedly, such an attractive electrostatic interaction is favored in polar media and, consequently, it is only evidenced with polar solvents. Apolar solvents such as hexane and toluene do not provide sufficient stabilization, and the concerted mechanism is preferred.

Contrary to typical stepwise cycloadddition reactions in which the rate-limiting step is the first one, ${ }^{46}$ in the reaction of nitrones with isocyanates in polar solvents, the rate-limiting step is the second one. This is a consequence of the enhanced stabilization of the first transition state due to the attractive electrostatic interaction. Indeed, the formation of the second bond takes place at the expense of breaking the attractive electrostatic interaction present in the intermediates of the reaction. The presence of stabilizing electrostatic interactions (favored by polar solvents) between the nitrone nitrogen and the isocyanate (nitrogen atom in the preferred path) are crucial for determining the stability of the intermediate, thus defining the mechanism in two steps.

\section{ASSOCIATED CONTENT}

\section{Supporting Information}

The Supporting Information is available free of charge on the ACS Publications website at DOI: 10.1021/acs.joc.5b02645.

Details on calculations corresponding to the reactions in the gas phase (1a and $\mathbf{2} \mathbf{a} ; \mathbf{1} \mathbf{b}$ and $\mathbf{2} \mathbf{b}$ ), dichloromethane $(\mathbf{1} \mathbf{a}-\mathbf{c}$ and $\mathbf{2 a}, \mathbf{b})$, hexane (1a and $2 \mathbf{a}$ ), toluene (1a and 2a), chloroform (1a and $\mathbf{2 a}$ ), and acetonitrile (1a and 2a). Details on NCI and ELF calculations. Cartesian coordinates of optimized structures (PDF)

Animations illustrating evolution of electron population (ELF analysis) along the reaction path (ZIP)

\section{AUTHOR INFORMATION}

\section{Corresponding Author}

*E-mail: pmerino@unizar.es.

\section{Notes}

The authors declare no competing financial interest.

\section{ACKNOWLEDGMENTS}

This work was supported by the Spanish Ministerio de Economía y Competitividad (MINECO) (project number CTQ2013-44367- C2-1-P), by the Fondos Europeos para el Desarrollo Regional (FEDER) and the Gobierno de Aragón (Zaragoza, Spain, Bioorganic Chemistry Group, E-10). The authors acknowledge the Institute of Biocomputation and Physics of Complex Systems (BIFI) at the University of 
Zaragoza for computer time at clusters Terminus and Memento. D. R.-L. thanks the Spanish Ministry of Education (MEC) for a predoctoral grant (FPU program).

\section{REFERENCES}

(1) (a) Confalone, P. N.; Huie, E. M. Org. React. 1988, 36, 1-174. (b) DeShong, P.; Lander, S. W., Jr.; Leginug, J. M.; Dickson, C. M. Dipolar Cycloadditions of Nitrones with Vinyl Ethers and Silane Derivatives. In Advances in Cycloaddition; Curran, D. P., Ed.; Jai Press, Inc.: Greenwich, CT, 1988; Vol. 1. (c) Gothelf, K. V.; Jorgensen, K. A. Chem. Commun. 2000, 1449-1458. (d) Merino, P. Nitrones and Cyclic Analogues. In Compounds with Two Carbon-Heteroatom Bonds: Heteroatom Analogues of Aldehydes and Ketones, Science of Synthesis; Pawda, A., Bellus, D., Eds.; Georg Thieme Verlag: Stuttgart-New York, 2004; Vol. 27, pp 511-580. (e) Merino, P. Nitrones and Cyclic Analogues (Update 2010). In Knowledge Updates 2010/4, Science of Synthesis; Bode, J. W., Carreira, E. M., Ishihara, K., Li, J. J., Marek, I., Oestreich, M., Schaumann, E., Yus, M., Eds.; Georg Thieme Verlag: Stuttgart-New York, 2011; Vol. 2010/4, pp 325-403. (f) Revuelta, J.; Cicchi, S.; Goti, A.; Brandi, A. Synthesis 2007, 2007, 485-504.

(2) Frederickson, M. Tetrahedron 1997, 53, 403-425.

(3) (a) Chiacchio, U.; Padwa, A.; Romeo, G. Curr. Org. Chem. 2009, 13, 422-447. (b) Martin, J. N.; Jones, R. C. F. Synthetic Applications of 1,3-Dipolar Cycloaddition Chemistry: Nitrones. In Synthetic Applications of 1,3-Dipolar Cycloaddition Chemistry toward Heterocycles and Natural Products; Padwa, A., Pearson, W. H., Eds.; Wiley: Chichester, United Kingdom, 2002; Vol. 59, pp 1-81.

(4) (a) Padwa, A.; Kline, D. N.; Koehler, K. F.; Matzinger, M.; Venkatramanan, M. K. J. Org. Chem. 1987, 52, 3909-3917. (b) Padwa, A.; Bullock, W. H.; Kline, D. N.; Perumattam, J. J. Org. Chem. 1989, 54, 2862-2869. (c) Padwa, A.; Meske, M.; Ni, Z. J. Tetrahedron Lett. 1993, 34, 5047-5050. (d) Malinina, J.; Tran, T. Q.; Stepakov, A. V.; Gurzhiy, V. V.; Starova, G. L.; Kostikov, R. R.; Molchanov, A. P. Tetrahedron Lett. 2014, 55, 3663-3666.

(5) (a) Pratt, R. N.; Stokes, D. P.; Taylor, G. A.; Brookes, P. C. J. Chem. Soc. C 1968, 2086-2089. (b) Pratt, R. N.; Stokes, D. P.; Taylor, G. A. J. Chem. Soc., Perkin Trans. 1 1975, 498-503. (c) Hafiz, M.; Taylor, G. A. J. Chem. Soc., Perkin Trans. 1 1980, 1700-1705. (d) Falshaw, C. P.; Hashi, N. A.; Taylor, G. A. J. Chem. Soc., Perkin Trans. 1 1985, 1837-1843.

(6) (a) Evans, A. R.; Martin, R.; Taylor, G. A.; Yap, C. H. M. J. Chem. Soc., Perkin Trans. 1 1987, 1635-40. (b) Richmond, E.; Duguet, N.; Slawin, A. M. Z.; Lebl, T.; Smith, A. D. Org. Lett. 2012, 14, 27622765. (c) Duguet, N.; Slawin, A. M. Z.; Smith, A. D. Org. Lett. 2009, $11,3858-3861$.

(7) Zinner, G.; Eghtessad, E. Arch. Pharm. 1979, 312, 907-913.

(8) (a) Mo, D.-L.; Pecak, W. H.; Zhao, M.; Wink, D. J.; Anderson, L. L. Org. Lett. 2014, 16, 3696-3699. (b) Holt, J.; Fiksdahl, A. J. Heterocycl. Chem. 2007, 44, 375-379. (c) Ritter, T.; Carreira, E. M. Angew. Chem., Int. Ed. 2005, 44, 936-938. (d) Coskun, N.; Parlar, A. Synth. Commun. 2006, 36, 997-1004.

(9) Bell, A. M. T.; Bridges, J.; Cross, R.; Falshaw, C. P.; Taylor, B. F.; Taylor, G. A.; Whittaker, I. G.; Begley, M. J. J. Chem. Soc., Perkin Trans. 1 1987, 2593-6.

(10) (a) Polienko, J. F.; Schanding, T.; Gatilov, Y. V.; Grigor'ev, I. A.; Voinov, M. A. J. Org. Chem. 2008, 73, 502-510. (b) van den Broek, L. A. G. M. Tetrahedron 1996, 52, 4467-4478. (c) Berezina, T. A.; Reznikov, V. A.; Volodarsky, L. B. Tetrahedron 1993, 49, 1069310704. (d) Balakirev, M. Y.; Khramtsov, V. V.; Berezina, T. A.; Martin, V. V.; Volodarsky, L. B. Synthesis 1992, 1992, 1223-1225.

(11) (a) Joseph, S. P.; Dhar, D. N. Tetrahedron 1986, 42, 59795983. (b) Joseph, S. P.; Dhar, D. N. Tetrahedron 1988, 44, 5209-5214.

(12) (a) Nacereddine, A. K.; Layeb, H.; Chafaa, F.; Yahia, W.; Djerourou, A.; Domingo, L. R. RSC Adv. 2015, 5, 64098-64105. (b) Emamian, S. RSC Adv. 2015, 5, 72959-72970. (c) Roca-Lopez, D.; Polo, V.; Tejero, T.; Merino, P. J. Org. Chem. 2015, 80, 4076-4083 and references cited therein.
(13) (a) Domingo, L. R.; Arno, M.; Merino, P.; Tejero, T. Eur. J. Org. Chem. 2006, 2006, 3464-3472. (b) Domingo, L. R.; Benchouk, W.; Mekelleche, S. M. Tetrahedron 2007, 63, 4464-4471.

(14) Roca-López, D.; Tejero, T.; Caramella, P.; Merino, P. Org. Biomol. Chem. 2014, 12, 517-525.

(15) Domingo, L. R. Eur. J. Org. Chem. 2000, 2000, 2265-2272.

(16) Kavitha, K.; Venuvanalingam, P. J. Chem. Soc. Perkin Trans. 2 2002, 2130-2139.

(17) (a) Celebi-Oelcuem, N.; Lam, Y.-h.; Richmond, E.; Ling, K. B.; Smith, A. D.; Houk, K. N. Angew. Chem., Int. Ed. 2011, 50, 1147811482 and S11478/1-S11478/37. (b) Richmond, E.; Ling, K. B.; Duguet, N.; Manton, L. B.; Çelebi-Ölçüm, N.; Lam, Y.-H.; Alsancak, S.; Slawin, A. M. Z.; Houk, K. N.; Smith, A. D. Org. Biomol. Chem. 2015, 13, 1807-1817.

(18) (a) Diez-Martinez, A.; Tejero, T.; Merino, P. Tetrahedron: Asymmetry 2010, 21, 2934-2943. (b) Roca-Lopez, D.; Tejero, T.; Merino, P. J. Org. Chem. 2014, 79, 8358-8365. (c) Roca-López, D.; Polo, V.; Tejero, T.; Merino, P. Eur. J. Org. Chem. 2015, 2015, 41434152.

(19) Frisch, M. J.; Trucks, G. W.; Schlegel, H. B.; Scuseria, G. E.; Robb, M. A.; Cheeseman, J. R.; Scalmani, G.; Barone, V.; Mennucci, B.; Petersson, G. A.; Nakatsuji, H.; Caricato, M.; Li, X.; Hratchian, H. P.; Izmaylov, A. F.; Bloino, J.; Zheng, G.; Sonnenberg, J. L.; Hada, M.; Ehara, M.; Toyota, K.; Fukuda, R.; Hasegawa, J.; Ishida, M.; Nakajima, T.; Honda, Y.; Kitao, O.; Nakai, H.; Vreven, T.; Montgomery, J. A., Jr.; Peralta, J. E.; Ogliaro, F.; Bearpark, M.; Heyd, J. J.; Brothers, E.; Kudin, K. N.; Staroverov, V. N.; Kobayashi, R.; Normand, J.; Raghavachari, K.; Rendell, A.; Burant, J. C.; Iyengar, S. S.; Tomasi, J.; Cossi, M.; Rega, N.; Millam, J. M.; Klene, M.; Knox, J. E.; Cross, J. B.; Bakken, V.; Adamo, C.; Jaramillo, J.; Gomperts, R.; Stratmann, R. E.; Yazyev, O.; Austin, A. J.; Cammi, R.; Pomelli, C.; Ochterski, J. W.; Martin, R. L.; Morokuma, K.; Zakrzewski, V. G.; Voth, G. A.; Salvador, P.; Dannenberg, J. J.; Dapprich, S.; Daniels, A. D.; Farkas, Ö.; Foresman, J. B.; Ortiz, J. V.; Cioslowski, J.; Fox, D. J. Gaussian 09, Revision D1; Gaussian, Inc.: Wallingford, CT, 2009.

(20) Zhao, Y.; Truhlar, D. G. Acc. Chem. Res. 2008, 41, 157-167.

(21) (a) Dunning, T. H., Jr. J. Chem. Phys. 1989, 90, 1007-1023. (b) Kendall, R. A.; Dunning, T. H., Jr.; Harrison, R. J. J. Chem. Phys. 1992, 96, 6796-6806. (c) Woon, D. E.; Dunning, T. H., Jr. J. Chem. Phys. 1993, 98, 1358-1371.

(22) Papajak, E.; Zheng, J.; Xu, X.; Leverentz, H. R.; Truhlar, D. G. J. Chem. Theory Comput. 2011, 7, 3027-3034.

(23) (a) Fukui, K. J. Phys. Chem. 1970, 74, 4161-4163. (b) Fukui, K. Acc. Chem. Res. 1981, 14, 363-368.

(24) (a) González, C.; Schlegel, H. B. J. Phys. Chem. 1990, 94, 55235527. (b) González, C.; Schlegel, H. B. J. Chem. Phys. 1991, 95, 58535860.

(25) (a) Barone, V.; Cossi, M.; Tomasi, J. J. Comput. Chem. 1998, 19, 404-417. (b) Cances, E.; Mennucci, B.; Tomasi, J. J. Chem. Phys. 1997, 107, 3032-3041. (c) Cossi, M.; Barone, V.; Cammi, R.; Tomasi, J. Chem. Phys. Lett. 1996, 255, 327-335. (d) Cossi, M.; Scalmani, G.; Rega, N.; Barone, V. J. Chem. Phys. 2002, 117, 43-54. (e) Tomasi, J.; Persico, M. Chem. Rev. 1994, 94, 2027-2094.

(26) (a) Johnson, E. R.; Keinan, S.; Mori-Sanchez, P.; ContrerasGarcia, J.; Cohen, A. J.; Yang, W. J. Am. Chem. Soc. 2010, 132, 64986506. (b) Lane, J. R.; Contreras-Garcia, J.; Piquemal, J.-P.; Miller, B. J.; Kjaergaard, H. G. J. Chem. Theory Comput. 2013, 9, 3263-3266.

(27) (a) Hennum, M.; Fliegl, H.; Gundersen, L.-L.; Eisenstein, O. J. Org. Chem. 2014, 79, 2514-2521. (b) Chaudret, R.; de Courcy, B.; Contreras-Garcla, J.; Gloaguen, E.; Zehnacker-Rentien, A.; Mons, M.; Piquemal, J.-P. Phys. Chem. Chem. Phys. 2014, 16, 9876-9891. (c) Armstrong, A.; Boto, R. A.; Dingwall, P.; Contreras-Garcia, J.; Harvey, M. J.; Mason, N. J.; Rzepa, H. S. Chem. Sci. 2014, 5, 20572071.

(28) (a) Aasheim, J. H.; Fliegl, H.; Uggerud, E.; Bonge-Hansen, T.; Eisenstein, O. New J. Chem. 2014, 38, 5975-5982. (b) Paton, R. S. Org. Biomol. Chem. 2014, 12, 1717-1720. 
(29) Contreras-Garcia, J.; Johnson, E. R.; Keinan, S.; Chaudret, R.; Piquemal, J.-P.; Beratan, D. N.; Yang, W. J. Chem. Theory Comput. 2011, 7, 625-632.

(30) Humphrey, W.; Dalke, A.; Schulten, K. J. Mol. Graphics 1996, $14,33$.

(31) (a) Savin, A.; Becke, A. D.; Flad, J.; Nesper, R.; Preuss, H.; Vonschnering, H. G. Angew. Chem., Int. Ed. Engl. 1991, 30, 409-412. (b) Savin, A.; Nesper, R.; Wengert, S.; Fassler, T. F. Angew. Chem., Int. Ed. Engl. 1997, 36, 1808.

(32) (a) Savin, A.; Silvi, B.; Coionna, F. Can. J. Chem. 1996, 74, 1088-1096. (b) Silvi, B. J. Mol. Struct. 2002, 614, 3-10. (c) Silvi, B.; Savin, A. Nature 1994, 371, 683. (d) Llusar, R.; Beltran, A.; Andres, J.; Noury, S.; Silvi, B. J. Comput. Chem. 1999, 20, 1517-1526. (e) Silvi, B.; Fourre, I.; Alikhani, M. E. Monatsh. Chem. 2005, 136, 855-879.

(f) Andres, J.; Berski, S.; Feliz, M.; Llusar, R.; Sensato, F.; Silvi, B. C. R. Chim. 2005, 8, 1400-1412.

(33) Noury, S.; Krokidis, X.; Fuster, F.; Silvi, B. Comput. Chem. 1999, 23, 597-604.

(34) (a) Bentabed-Ababsa, G.; Derdour, A.; Roisnel, T.; Saez, J. A.; Perez, P.; Chamorro, E.; Domingo, L. R.; Mongin, F. J. Org. Chem. 2009, 74, 2120-2133. (b) Domingo, L. R.; Chamorro, E.; Perez, P. J. Org. Chem. 2008, 73, 4615-4624. (c) Domingo, L. R.; Chamorro, E.; Perez, P. Org. Biomol. Chem. 2010, 8, 5495-5504.

(35) Legault, C. Y. Université de Sherbrooke, 2009, http://www. cylview.org.

(36) Aldonitrones are always in the $Z$-form with the exception of those having an electron-withdrawing group at the nitrone carbon. See ref 15 a.

(37) Any optimization starting from different points converged to TS1a-S, the concerted transition structure TS1a-C not being found in any case.

(38) Neumann, F.; Lambert, C.; Schleyer, P. v. R. J. Am. Chem. Soc. 1998, 120, 3357-3370.

(39) Merino, P.; Tejero, T.; Diez Martinez, A. J. Org. Chem. 2014, 79, 2189-2202.

(40) (a) Kantorowski, E. J.; Brown, S. P.; Kurth, M. J. J. Org. Chem. 1998, 63, 5272-5274. (b) Kaim, L. E.; Gacon, A. Tetrahedron Lett. 1997, 38, 3391-3394. (c) Mukaiyama, T.; Hoshino, T. J. Am. Chem. Soc. 1960, 82, 5339-5342. For an interactive model see: http://www. chemtube3d.com/ClaydenNitrileOxide.html.10.1021/ja01505a017

(41) Zhang, C.; Zhu, Y.; Wei, D.; Sun, D.; Zhang, W.; Tang, M. J. Phys. Chem. A 2010, 114, 2913-2919.

(42) Troconiz, G. F. d.; Retana, A. M. O. d.; Rubiales, G.; Palacios, F. J. Org. Chem. 2014, 79, 5173-5181.

(43) (a) Ivanova, E. V.; Muchall, H. M. J. Phys. Chem. A 2007, 111, 10824-10833. (b) Samuilov, A. Y.; Balabanova, F. B.; Samuilov, Y. D.; Konovalov, A. I. Russ. J. Org. Chem. 2012, 48, 164-174. (c) Wen, Z.; Hu, W.; Chi, X.; Wang, X.; Tian, D.; Wang, M.; Liu, J.; Ma, X.; Pang, A. Commun. Comput. Chem. 2014, 2, 22-35.

(44) Bharatam, P. V.; Moudgil, R.; Kaur, D. J. Phys. Chem. A 2003, 107, 1627-1634.

(45) Bürgi, H. B.; Dunitz, J. D.; Lehn, J. M.; Wipff, G. Tetrahedron 1974, 30, 1563-1572.

(46) (a) Lan, Y.; Houk, K. N. J. Am. Chem. Soc. 2010, 132, 1792117927. (b) Domingo, L. R.; Aurell, M. J.; Perez, P. RSC Adv. 2014, 4, 16567-16577. (c) Cantillo, D.; Avalos, M.; Babiano, R.; Cintas, P.; Jimenez, J. L.; Light, M. E.; Palacios, J. C.; Porro, R. J. Org. Chem. 2014, 79, 4201-4205. 